\title{
Determinants of low APGAR score in newborns delivered at Lemlem Karl general hospital, Northern Ethiopia, 2018: a case control study
}

Mussie Mulugeta Gebremedhin ( $\sim$ mussiemulugeta@gmail.com )

Aksum University

Mengistu Welday Gebremichael

Mekelle University

Berhane Gebreegizabiher Gebremichael

Mekelle University College of Health Sciences

Mihrete-ab Mehari Reda

Mekelle University College of Health Sciences

Tesfay Adhena Hailu

Aksum University

Gebrekiros Aregawi Gebremeskel

Aksum University

Kenean Getaneh Tlaye

Woldia University

Henok Kumsa Meikena

Woldia University

Nigus Bililign Yimer

Woldia University

Research article

Keywords: Determinant factors, Low Apgar score, Northern Ethiopia, Case Control.

Posted Date: September 24th, 2020

DOl: https://doi.org/10.21203/rs.3.rs-32019/v2

License: (c) (i) This work is licensed under a Creative Commons Attribution 4.0 International License.

Read Full License 


\section{Abstract}

BACKGROUND: The Apgar score is a method to quickly summarize the health of newborn children. It establishes a simple and clear classification of newborns, which could be used to predict survival and to compare methods of resuscitation and perinatal experience across hospitals and obstetric practices. Low Apgar score is associated with various immediate and long-term adverse health outcomes of newborns. Hence; in order to decrease the risk/complications, identifying the determinant factors of low Apgar is crucial to act on the modifiable risk factors. This study is aimed to investigate the determinant factors of a low Apgar score in newborn children.

METHOD: The study was conducted in Lemelem Karl general hospital; northern Ethiopia. An institutionalbased unmatched, case-control study was implemented. Data were retrieved from medical charts of 662 newborns' mothers who gave birth in the hospital from Sep 2014 to Sep 2017. Among these, 221 of them were cases (charts of mothers whose newborns' fifth minute Apgar score was $<7$ ) and 441 of them were controls (charts of mothers whose newborns' Apgar score was 7 and above). Data was collected using a pretested and structured checklist using systematic sampling and data was entered \& analyzed using SPSS version 20. Binary and multivariable logistic regression was done to determine the association and statistical significance was declared at $P$-value of $\leq 0.05$.

RESULTS: This study revealed that low Apgar score was significantly associated with antepartum hemorrhage [Adjusted odds ratio (AOR) 3.509; 95\% confidence interval (CI) 1.526-8.067), $P=0.003$ ], pregnancy-induced hypertensive disorders [AOR 2.69; 95\% Cl (1.351-5.357), $P=0.005]$, prolonged second stage of labor [AOR 2.63; 95\% Cl (1.399-4.944), $P=0.003$ ], Cesarean delivery [AOR 2.005; 95\% Cl (1.2233.287), $P=0.006$ ],meconium-stained liquor [AOR 6.955; 95\% Cl (3.721-13.001), $P<0.001]$, and low birth weight [AOR 4.38; 95\% Cl (2.216-8.657), $P<0.001]$.

CONCLUSION: Result from this study showed a remarkable linkage of low Apgar score with antepartum hemorrhage, pregnancy-induced hypertensive disorders, meconium-stained liquor, and low birth weight. Therefore, meticulous antenatal care and labour management service are recommended to prevent low Apgar score and the concomitant neonatal death.

\section{Background}

The first minutes after birth are crucial for newborn's adaptation to extra-uterine life [1]. The Apgar score comprises five components Color, Heart Rate, Reflexes, Muscle Tone, and Respiration; each assigned a score of 0,1 , or 2 . The score is reported at $1^{\text {st }}$ and $5^{\text {th }}$ minutes after birth for all infants, and at 5 -minute intervals thereafter until 20 minutes for infants with a score of less than 7 [2]. Apgar score can be classified as reassuring, moderately abnormal and low if the score is $7-10,4-6$, and $0-3$ respectively in the term and late-term infants [3].

Low $1^{\text {st }}$ minute Apgar score has not been found to correlate with future outcomes, such as negative neurological outcomes, and is poor sensitivity markers for asphyxia. However, low $5^{\text {th }}$ minute Apgar score 
is associated with increased mortality in premature newborns [4-8], and also associated with various types of future developmental and cognitive problems [9].

Since it is the only form of evaluation in developing countries, where laboratory tests may not be available, the low cost of the Apgar score is useful in identifying children who need additional care, even in the absence of laboratory data [10].

Globally, 5.9 and 2.7 million under-five children and neonates died in 2015 respectively [11]. In SubSaharan Africa, the under-five and neonatal mortality rates were $83 \& 29$, deaths per 1,000 live births. The seven countries with an under-five mortality rate above 100 are all located in sub-Saharan Africa [11].

In Ethiopia 1 in every 35 children dies within the first month, 1 in every 21 children dies before celebrating the first birthday, and 1 of every 15 children dies before reaching the fifth birthday [12].

Concerning the magnitude of low Apgar score (LAS), studies conducted in Portugal, Brazil, Denmark, Iran, Indonesia, and Sweden showed prevalence's of $3.8 \%, 0.4 \%, 0.7 \%, 3.3 \%, 5.4 \%$, and $0.7 \%$ respectively [1318]. A previous study conducted in Ghana showed that the prevalence of LAS was $1.9 \%$ [19]. According to the study conducted in Gondar University referral hospital, North West Ethiopia in 2013, the proportion of LAS was $13.8 \%$ [20].

Globally, the academic community has extensively explored the determinant factors of LAS. However, few researches have been conducted to identify the determinant factors of LAS in the study area and in Ethiopia. Hence, there is a need to carry out research to pinpoint the determinant factors of LAS. On the other hand, identifying the determinant factors of LAS will be useful in designing guidelines to prevent contributing factors and reduce the costs imposed on the health care system and to provide community health.

\section{Methods}

\section{Study design}

An institutional-based retrospective unmatched case control study was conducted from September 2017 to January 2018 to assess the determinant factors of a low Apgar score in newborns delivered at Lemlem Karl general hospital using a medical chart review.

\section{Study area}

The hospital is located in Maichew town, $662 \mathrm{~km}$ north of Addis Ababa, the capital city of Ethiopia and $120 \mathrm{~km}$ south of Mekelle, the capital city of Tigray regional state. The hospital has 132 beds and it is estimated that around 1000 women give birth annually in the hospital.

\section{Sample size estimation and sampling procedures}


The sample size was calculated using Open Epi Data statistical software. A 2:1 ratio of controls to cases, $95 \%$ confidence level and power of $80 \%$ was assumed. Taking proportion of grand-multiparity among exposed which is 12.09 and 5.4\% among non - exposed [27], it yielded a total sample size of 662 (221 charts of mothers whose newborns' $5^{\text {th }}$ minute Apgar score is $<7$ (cases) and 441 charts of mothers whose newborns' $5^{\text {th }}$ minute Apgar score is $\geq 7$ (controls)) (Table 1 ).

Table 1: A table showing sample size calculation based on proportions of different variables from various literatures with $95 \%$ level of confidence, $80 \%$ power and 2:1 ratio of control to cases, 2017.

\begin{tabular}{|c|c|c|c|c|c|c|}
\hline No & Variables & $\begin{array}{l}\text { Proportion of controls } \\
\text { with exposure }\end{array}$ & $\begin{array}{l}\text { Proportion of cases } \\
\text { with exposure }\end{array}$ & OR & $\begin{array}{l}\text { Sample } \\
\text { size }\end{array}$ & References \\
\hline \multirow{3}{*}{1} & \multirow{3}{*}{$\begin{array}{l}\text { Early onset } \\
\text { preeclampsia }\end{array}$} & \multirow{3}{*}{$19.4 \%$} & \multirow{3}{*}{$70.79 \%$} & \multirow{3}{*}{10.7} & $\begin{array}{l}\text { Cases : } \\
13\end{array}$ & \multirow{3}{*}{$\begin{array}{l}\text { Susilo SA; } \\
\text { et.al } \\
2015\end{array}$} \\
\hline & & & & & $\begin{array}{l}\text { Control } \\
: 26\end{array}$ & \\
\hline & & & & & $\begin{array}{l}\text { Total : } \\
39\end{array}$ & \\
\hline \multirow{3}{*}{2} & \multirow{3}{*}{ Grand multiparty } & \multirow{3}{*}{$5.4 \%$} & \multirow{3}{*}{$12.09 \%$} & \multirow{3}{*}{2.41} & $\begin{array}{l}\text { Cases: } \\
221\end{array}$ & \multirow[t]{3}{*}{$\begin{array}{l}\text { Mgaya AH } \\
\text { et.al; }\end{array}$} \\
\hline & & & & & $\begin{array}{l}\text { Control: } \\
441\end{array}$ & \\
\hline & & & & & $\begin{array}{l}\text { Total: } \\
662\end{array}$ & \\
\hline \multirow{3}{*}{3} & \multirow{3}{*}{ Nulliparity } & \multirow{3}{*}{47.3} & \multirow{3}{*}{68.39} & \multirow{3}{*}{2.41} & $\begin{array}{l}\text { Cases: } \\
71\end{array}$ & \multirow{3}{*}{$\begin{array}{l}\text { Berglund S } \\
\text {; et.al } \\
2010\end{array}$} \\
\hline & & & & & $\begin{array}{l}\text { Control: } \\
142\end{array}$ & \\
\hline & & & & & $\begin{array}{l}\text { Total: } \\
213\end{array}$ & \\
\hline
\end{tabular}

Charts of mothers who gave birth in Lemlem Karl General Hospital from September 11, 2014, to September 10, 2017, which were selected using systematic sampling were reviewed in this study. All neonates born after 34 completed weeks of gestation in the hospital were included in the study. Newborns whose fifth minute Apgar score $<7$ were regarded as cases and newborns whose fifth minute Apgar score $\geq 7$ were taken as a control group. Newborns with gross congenital anomalies incompatible with life, neonates born via elective cesarean section (CS), deliveries of unknown gestational age (unknown last normal menstrual period and no ultrasound estimation), twin pregnancy, neonates born to mothers with pre-existing medical disease and newborns who had not been given an Apgar score at fifth minutes of birth and incomplete records (if at least 3 variables were missed) were excluded from the study. 
Data were retrieved from the sampled mothers' chart using a structured checklist which was developed after reviewing variables discussed in various literatures to enable the researchers to collect data on socio-demographic status, obstetric factors, and fetal factors.

The Apgar score comprises five components; color, Heart Rate, Reflexes, Muscle tone, and Respiration. Each assigned a score of 0,1 or 2 . The score is reported at first and fifth minute after birth for all infants, and at five minute intervals thereafter until 20 minutes for infants with a score of less than 7 [2]. In Lemelem Karl General Hospital, Apgar score was recorded by the BSc midwives, MSc midwives or by the obstetrician.

\section{Data collection tools and techniques}

Prior to the data collection, the checklist was reviewed by senior researchers for its validity. Four graduated midwives with previous experience in data collection were employed as data collectors and two MSc in Clinical Midwifery students were recruited as supervisors. Three days of training on data collection was provided. The data were collected retrospectively from medical charts of the newborn's mother. The collected data were checked by supervisors every day for its completeness and the principal investigator monitored the overall tasks. The checklist was pretested in $10 \%$ of the calculated sample size in the same hospital on charts of mothers who visited this hospital prior to the study period. After this pretest was undertaken, two explanatory variables (educational status and annual income) were omitted from the checklist.

\section{Data processing and analysis}

The data were checked for completeness, then coded, entered, and analyzed using Statistical Package for Social Sciences (SPSS) version 20. Descriptive statistics were used to compute frequency, percentile, mean and median of different variables. A Binary logistic regression model was employed to test the association between the dependent and independent variables. Low Apgar score was the dependent variable. Socio-demographic and fetal factors such as sex, gestational age, fetal presentation, and birth weight are independent variables. Moreover, obstetric factors such as parity, gestation, the onset of labor, duration of labor, mode of delivery, augmentation of labor, pregnancy-induced hypertensive disorders, antepartum hemorrhage, meconium-stained liquor, premature rupture of membrane, duration of the premature rupture of the membrane are independent variables. All variables with P-value $\leq 0.25$ in the binary logistic regression were included in the multivariable logistic analysis. The Hosmer-Lemeshow goodness-of-fit with enter procedure was used to test for model fitness $(P=0445)$. The magnitude of the association was measured using odds ratio at $95 \%$ confidence interval. Variables with $p$-value $<0.05$ in the multivariable logistic regression analysis was considered as significant and independent determinant factor of LAS.

\section{Results}

Socio-demographic characteristics of the study participants

Page 5/17 
A total of 662 charts of newborns' mothers (221 cases and 441 controls) were reviewed in this study. The mean $( \pm S D)$ age of mothers was $28( \pm 6)$ and $27( \pm 5)$ years among cases and controls respectively. Sociodemographic characteristics of the study participants are listed in Table 2.

Table 2: Socio-demographic characteristic of mothers, Lemlem Karl general hospital, northern Ethiopia; 2018. $(\mathrm{N}=662)$

\begin{tabular}{|c|c|c|c|c|}
\hline \multirow{3}{*}{ Variables } & \multirow{3}{*}{ Categories } & \multicolumn{2}{|c|}{ Fifth Minute ApgarScore } & \multirow[b]{2}{*}{ Total } \\
\hline & & Cases & Controls & \\
\hline & & N (\%) & N (\%) & N (\%) \\
\hline \multirow[t]{3}{*}{ Age of mothers } & $<=19$ & $10(4.5)$ & $25(5.7)$ & $35(5.3)$ \\
\hline & $20-34$ & $188(85.1)$ & $385(87.3)$ & $573(86.6)$ \\
\hline & $>=35$ & $23(10.4)$ & $31(7.0)$ & $54(8.2)$ \\
\hline \multirow[t]{2}{*}{ Residence } & Urban & $120(54.3)$ & $243(55.1)$ & $363(54.8)$ \\
\hline & Rural & $101(45.7)$ & $198(44.9)$ & $299(45.2)$ \\
\hline
\end{tabular}

\section{Obstetric characteristics of mothers among cases and controls}

This study revealed that proportion/percentage/magnitude of prolonged second stage of labor PSSL among mothers of the cases was $15.8 \%$ which is higher than among mothers of the controls, $6.1 \%$. Additionally, $7.2 \%$ of mothers among cases and $3.2 \%$ of mothers among controls were diagnosed with antepartum hemorrhage (APH) in the current pregnancy. More than one-fifth (21.7\%) mothers of the cases and (5.7\%) mothers of the controls were diagnosed with the pregnancy-induced hypertensive disorder (PIHD). The obstetric characteristic of mothers among cases and controls is shown in Table 3.

Table 3: Obstetric characteristics of mothers among cases and controls, Lemlem Karl general hospital, northern Ethiopia, $2018(\mathrm{~N}=662)$ 


\begin{tabular}{|c|c|c|c|c|}
\hline \multirow[t]{2}{*}{ riables } & \multirow[t]{2}{*}{ Categories } & \multicolumn{2}{|c|}{$\begin{array}{c}\text { Fifth Minute Apgar } \\
\text { Score }\end{array}$} & \multirow{2}{*}{$\begin{array}{l}\text { Total } \\
\text { N (\%) }\end{array}$} \\
\hline & & $\begin{array}{l}\text { Cases } \\
\mathrm{N}(\%)\end{array}$ & $\begin{array}{l}\text { Controls } \\
\text { N (\%) }\end{array}$ & \\
\hline ity & $\begin{array}{l}\text { Primipara } \\
\text { Multipara } \\
\text { Grandmultipara }\end{array}$ & $\begin{array}{c}102(46.2) \\
96(43.4) \\
23(10.4)\end{array}$ & $\begin{array}{c}188(42.6) \\
220(49.9) \\
33(7.5)\end{array}$ & $\begin{array}{c}290(43.8) \\
316(47.7) \\
56(8.5)\end{array}$ \\
\hline$\overline{\mathrm{H}}$ & $\begin{array}{l}\text { Yes } \\
\text { No }\end{array}$ & $\begin{array}{c}16(7.2) \\
205(92.8)\end{array}$ & $\begin{array}{c}14(3.2) \\
427(96.8)\end{array}$ & $\begin{array}{c}30(4.5) \\
632(95.5)\end{array}$ \\
\hline $\begin{array}{l}\text { gnancy induced hypertensive } \\
\text { order }\end{array}$ & $\begin{array}{l}\text { Yes } \\
\text { No }\end{array}$ & $\begin{array}{c}48(21.7) \\
173(78.3)\end{array}$ & $\begin{array}{c}25(5.7) \\
416(94.3)\end{array}$ & $\begin{array}{c}73(11.0) \\
589(89.0)\end{array}$ \\
\hline $\begin{array}{l}\text { mature Rupture of membrane } \\
(\mathrm{OM})\end{array}$ & $\begin{array}{l}\text { Yes } \\
\text { No }\end{array}$ & $\begin{array}{c}28(12.7) \\
193(87.3)\end{array}$ & $\begin{array}{c}30(6.8) \\
411(93.2)\end{array}$ & $\begin{array}{c}58(8.8) \\
604(91.2)\end{array}$ \\
\hline ation of the PPROM & $\begin{array}{l}<12 \text { hours } \\
>=12 \text { hours }\end{array}$ & $\begin{array}{l}11(39.3) \\
17(60.7)\end{array}$ & $\begin{array}{l}12(40.0) \\
18(60.0)\end{array}$ & $\begin{array}{l}23(39.7) \\
35(60.3)\end{array}$ \\
\hline set of labor & $\begin{array}{l}\text { Spontaneous } \\
\text { Induced }\end{array}$ & $\begin{array}{c}184(83.3) \\
37(16.7)\end{array}$ & $\begin{array}{c}412(93.4) \\
29(6.6)\end{array}$ & $\begin{array}{c}596(90.0) \\
66(10.0)\end{array}$ \\
\hline longed second stage of labor & $\begin{array}{l}\text { Yes } \\
\text { No }\end{array}$ & $\begin{array}{c}35(15.8) \\
186(84.2)\end{array}$ & $\begin{array}{c}27(6.1) \\
414(93.9)\end{array}$ & $\begin{array}{c}62(9.4) \\
600(90.6)\end{array}$ \\
\hline conium stained liquor & $\begin{array}{l}\text { Yes } \\
\text { No }\end{array}$ & $\begin{array}{c}50(22.6) \\
171(77.4)\end{array}$ & $\begin{array}{c}18(4.1) \\
423(95.9)\end{array}$ & $\begin{array}{c}68(10.3) \\
594(89.7)\end{array}$ \\
\hline jmentation of labor & $\begin{array}{l}\text { Yes } \\
\text { No }\end{array}$ & $\begin{array}{c}25(11.3) \\
196(88.7)\end{array}$ & $\begin{array}{c}44(10.0) \\
397(90.0)\end{array}$ & $\begin{array}{c}69(10.4) \\
593(89.6)\end{array}$ \\
\hline de of delivery & $\begin{array}{l}\text { Spontaneous Vaginal } \\
\text { Delivery } \\
\text { Operative Vaginal Delivery } \\
\text { Caesarean Delivery } \\
\text { Vaginal Breech Delivery }\end{array}$ & $\begin{array}{c}99(44.8) \\
39(17.6) \\
69(31.2) \\
14(6.3)\end{array}$ & $\begin{array}{c}313(71.0) \\
47(10.7) \\
73(16.6) \\
8(1.8)\end{array}$ & $\begin{array}{c}412(62.2) \\
86(13.0) \\
142(21.5) \\
22(3.3)\end{array}$ \\
\hline
\end{tabular}

\section{Characteristics of Newborns}

Of all study subjects, nearly half (48.4\%) of cases and more than half of the controls (51.7\%) were females. Furthermore, regarding the gestational age (GA) three-fourth (78.3\%) of cases and the majority $(89.8 \%)$ of controls were terms. The characteristics of newborns are shown in Table 4.

Table 4: Characteristics of newborns delivered at Lemlem Karl general hospital, northern Ethiopia, 2018. (N= 662) 


\begin{tabular}{|c|c|c|c|c|}
\hline \multirow{3}{*}{ Variables } & \multirow{3}{*}{ Categories } & \multicolumn{2}{|c|}{ Fifth Minute Apgar Score } & \multirow[b]{2}{*}{ Total } \\
\hline & & Cases & Controls & \\
\hline & & $\mathbf{N}(\%)$ & $\mathbf{N}(\%)$ & $\mathrm{N}(\%)$ \\
\hline \multirow[t]{2}{*}{ Sex } & Female & $107(48.4)$ & $228(51.7)$ & $335(50.6)$ \\
\hline & Male & $114(51.6)$ & $213(48.3)$ & $327(49.4)$ \\
\hline \multirow[t]{3}{*}{ Gestational Age } & Late Preterm (34-36+6 weeks) & $41(18.6)$ & $29(6.6)$ & $70(10.6)$ \\
\hline & Term & 173(78.3) & 396(89.8) & $569(86.0)$ \\
\hline & Post term & $7(3.2)$ & $16(3.6)$ & $23(3.5)$ \\
\hline \multirow[t]{3}{*}{ Fetal presentation } & Breech & $23(10.4)$ & $11(2.5)$ & $34(5.1)$ \\
\hline & Vertex & 196(88.7) & $427(96.8)$ & $623(94.1)$ \\
\hline & Non-Vertex* & $2(0.9)$ & $3(0.7)$ & $5(0.8)$ \\
\hline \multirow[t]{3}{*}{ Birth weight } & Low birth weight & $52(23.5)$ & $24(5.4)$ & $76(11.5)$ \\
\hline & Normal birth weight & $166(75.1)$ & $413(93.7)$ & $579(87.5)$ \\
\hline & Macrosomia & $3(1.4)$ & $4(0.9)$ & $7(1.1)$ \\
\hline
\end{tabular}

*= Brow presentation and Shoulder presentation

\section{Determinant factors for low Apgar score}

This study encompassed 14 independent variables. Both bivariate and multivariable logistic regression analyses were done to see the association of the independent variables and LAS. Low Apgar score is significantly associated with the age of mothers, parity, antepartum hemorrhage (APH), pregnancyinduced hypertensive disorder (PIHD), premature rupture of membrane (PROM), the onset of labor, the prolonged second stage of labor (PSSL), meconium-stained liquor, mode of delivery, gestational age (GA), fetal presentation, and fetal birth weight in the bivariate analysis. However, in the multivariate logistic regression analysis APH, PIHD, PSSL, MSL, mode of delivery, and fetal birth weight was associated with the low Apgar score.

Accordingly, the odds of having LAS among neonates born to mothers with PSSL were 2.6 times [AOR 2.63; 95\% Cl (1.399-4.944), $P=0.003$ ], higher compared to their counterparts. Moreover, the likelihood of encountering LAS was 3.5 times [AOR 3.509; 95\% Cl 1.526-8.067), $P=0.003$ ] higher among neonates born to mothers those who diagnosed with APH. In this study, the higher odds of developing LAS were also observed among neonates born to mothers with PIHD [AOR 2.69; 95\% Cl (1.351-5.357), $P=0.005]$, than newborns born to mothers without PIHD. Likewise, the odds of exhibited low AS among neonates with low birth weight was 4.38 times [AOR 4.38; 95\% Cl (2.216-8.657), $P<0.001$ ], higher compared to those of 
their counterparts. The logistic regression table indicating the association of all independent variables with the dependent variable is shown in Table 5.

Table 5: Bivariate and multivariate analysis of determinant factors of low Apgar score in newborns delivered at Lemlem Karl General Hospital, Maychew Town, Tigray, Ethiopia, 2018. 


\begin{tabular}{|c|c|c|c|c|c|}
\hline \multirow[t]{2}{*}{ Variables } & \multirow[t]{2}{*}{$\begin{array}{l}\text { Cases } \\
\text { no(\%) }\end{array}$} & \multirow[t]{2}{*}{$\begin{array}{c}\text { Controls } \\
\text { no(\%) }\end{array}$} & \multicolumn{2}{|c|}{ Odds ratios $(95 \% \mathrm{CI})$} & \multirow{2}{*}{$\begin{array}{c}\text { P- } \\
\text { Value }\end{array}$} \\
\hline & & & Unadjusted & Adjusted & \\
\hline \multicolumn{6}{|l|}{ Age of mothers(Yrs.) } \\
\hline $20-34$ & $188(85.1)$ & $385(87.3)$ & 1 & 1 & - \\
\hline$<=19$ & $10(4.5)$ & $25(5.7)$ & $0.819(0.385-$ & $0.711(0.279-1.865)$ & 0.604 \\
\hline$\geq 35$ & $23(10.4)$ & $31(7.0)$ & $\begin{array}{c}1.741) \\
1.519(0.862- \\
2.678)^{*}\end{array}$ & $1.646(0.728-3.724)$ & 0.148 \\
\hline \multicolumn{6}{|l|}{ Residence } \\
\hline Urban & $120(54.3)$ & $243(55.1)$ & 1 & - & - \\
\hline Rural & $101(45.7)$ & 198(44.9) & $\begin{array}{c}1.033(0.747- \\
1.429)\end{array}$ & - & 0.845 \\
\hline \multicolumn{6}{|l|}{ Parity } \\
\hline Multipara & $96(43.4)$ & $220(49.9)$ & 1 & 1 & - \\
\hline Primipara & $102(46.2)$ & $188(42.6)$ & $1.243(0.885-$ & $1.120(0.723-1.734)$ & 0.209 \\
\hline Grandmultipara & $23(10.4)$ & $33(7.5)$ & $\begin{array}{c}1.747) \\
1.597(0.891- \\
2.864)^{*}\end{array}$ & $1.595(0.723-1.734)$ & 0.116 \\
\hline \multicolumn{6}{|c|}{ Antepartum hemorrhage } \\
\hline Yes & $16(7.2)$ & $14(3.2)$ & $2.380(1.140-$ & $3.509(1.526-8.067)$ & 0.003 \\
\hline No & $205(92.8)$ & $427(96.8)$ & $\begin{array}{c}4.971) * \\
1\end{array}$ & $\begin{array}{c}* * \\
1\end{array}$ & - \\
\hline \multicolumn{6}{|c|}{ Pregnancy induced hypertensive disorder } \\
\hline Yes & $48(21.7)$ & $25(5.7)$ & $4.617(2.759-$ & $2.69(1.351-5.357)$ & 0.005 \\
\hline No & 173(78.3) & $416(94.3)$ & $\begin{array}{c}7.726) * \\
1\end{array}$ & $\begin{array}{c}* * \\
1\end{array}$ & - \\
\hline \multicolumn{6}{|c|}{ Premature Rupture of membrane (PROM) } \\
\hline Yes & $28(12.7)$ & $30(6.8)$ & $1.988(1.155-$ & $1.669(0.850-3.278)$ & 0.013 \\
\hline No & 193(87.3) & $411(93.2)$ & $\begin{array}{c}3.420) * \\
1\end{array}$ & 1 & - \\
\hline \multicolumn{6}{|l|}{ Duration of PROM } \\
\hline$<12$ hours & 11(39.3) & $12(40.0)$ & 1 & - & - \\
\hline$\geq 12$ hours & $17(60.7)$ & 18(60.0) & $\begin{array}{l}1.030(0.359- \\
2.953)\end{array}$ & - & 0.956 \\
\hline \multicolumn{6}{|l|}{ Onset of labor } \\
\hline Spontaneous & $184(83.3)$ & $412(93.4)$ & 1 & 1 & - \\
\hline Induced & $37(16.7)$ & $29(6.6)$ & $\begin{array}{l}2.857(1.705- \\
\quad 4.787)^{*}\end{array}$ & $1.858(0.924-3.738)$ & $<0.001$ \\
\hline \multicolumn{6}{|c|}{ Prolonged second stage of labor } \\
\hline Yes & $35(15.8)$ & $27(6.1)$ & $2.885(1.697-$ & $2.630(1.399-4.944)$ & 0.003 \\
\hline No & $186(84.2)$ & $414(93.9)$ & $\begin{array}{c}4.907) * \\
1\end{array}$ & $\begin{array}{l}* * \\
1\end{array}$ & - \\
\hline \multicolumn{6}{|c|}{ Meconium stained liquor } \\
\hline Yes & $50(22.6)$ & $18(4.1)$ & 6.871(3.897- & 6.955(3.721- & $<0.001$ \\
\hline No & $171(77.4)$ & 423(95.9) & $\begin{array}{c}12.117) * \\
1\end{array}$ & $\begin{array}{c}13.001)^{* *} \\
1\end{array}$ & \\
\hline \multicolumn{6}{|c|}{ Augmentation of labor } \\
\hline Yes & $25(11.3)$ & $44(10.0)$ & 1.151(0.684- & - & - \\
\hline
\end{tabular}




\begin{tabular}{|c|c|c|c|c|c|}
\hline No & 196(88.7) & 397(90.0) & $\begin{array}{c}1.935) \\
1\end{array}$ & - & 0.596 \\
\hline \multicolumn{6}{|l|}{ Mode of delivery } \\
\hline SVD & $99(44.8)$ & $313(71.0)$ & 1 & 1 & - \\
\hline Operative Vaginal & $39(17.6)$ & $47(10.7)$ & $2.623(1.622-$ & $1.568(0.868-2.835)$ & 0.136 \\
\hline CS & $69(31.2)$ & $73(16.6)$ & $4.244) *$ & $2.005(1.223-3.287)$ & 0.006 \\
\hline Vaginal Breech & $14(6.3)$ & $8(1.8)$ & $\begin{array}{c}2.988(2.005- \\
4.455) * \\
5.533(2.255- \\
13.576) *\end{array}$ & $\begin{array}{c}* * \\
2.679(0.597- \\
12.024\end{array}$ & 0.198 \\
\hline \multicolumn{6}{|l|}{ Sex of neonates } \\
\hline Female & $107(48.4)$ & $228(51.7)$ & 1 & - & - \\
\hline Male & $114(51.6)$ & $213(48.3)$ & $\begin{array}{c}1.140(0.825- \\
1.576)\end{array}$ & - & 0.426 \\
\hline \multicolumn{6}{|l|}{ Gestational Age } \\
\hline Term & 173(78.3) & 396(89.8) & 1 & 1 & - \\
\hline $\begin{array}{l}\text { Late Preterm (34-36+6 } \\
\text { weeks) }\end{array}$ & $41(18.6)$ & $29(6.6)$ & $\begin{array}{l}3.236(1.947- \\
5.378) *\end{array}$ & $1.354(0.666-2.750)$ & $<0.001$ \\
\hline Post term & $7(3.2)$ & $16(3.6)$ & $\begin{array}{c}1.001(0.405- \\
2.478)\end{array}$ & $0.981(0.333-2.894)$ & 0.998 \\
\hline \multicolumn{6}{|l|}{ Fetal presentation } \\
\hline Vertex & 196(88.7) & $427(96.8)$ & 1 & 1 & - \\
\hline Breech & $23(10.4)$ & $11(2.5)$ & $4.555(2.177-$ & $2.080(0.590-7.330)$ & $<0.001$ \\
\hline Non-vertex & $2(0.9)$ & $3(0.7)$ & $\begin{array}{c}9.530) * \\
1.452(0.241- \\
8.762)\end{array}$ & $\begin{array}{c}2.019(0.313- \\
13.036)\end{array}$ & 0.684 \\
\hline \multicolumn{6}{|l|}{ Fetal birth weight } \\
\hline Normal birth weight & $166(75.1)$ & $413(93.7)$ & 1 & 1 & - \\
\hline Low birth weight & $52(23.5)$ & $24(5.4)$ & 5.391(3.217- & $4.380(2.216-8.657)$ & $<0.001$ \\
\hline Macrosomia & $3(1.4)$ & $4(0.9)$ & $\begin{array}{c}9.032) * \\
1.866(0.413- \\
8.428)\end{array}$ & $\begin{array}{c}* * \\
2.655(0.474- \\
14.876)\end{array}$ & 0.267 \\
\hline
\end{tabular}

**: Significantly associated variables in multivariate logistic regression

1: Reference group, $\mathrm{n}$ (number), \% (Percent)

SVD: Spontaneous vaginal delivery

CS: Cesarean section

Hosmer and Lemeshow Test: $\mathrm{P}=0.445$

\section{Discussion}

In addition, low Apgar score was found to be significantly associated with PIHD [AOR 2.69; 95\% Cl (1.3515.357), $P=0.005$ ], in this study. This finding is in line with the studies done in Sweden and India; which showed a statistically significant association between PIHD and LAS [30, 31]. This could be ascribed to the fact that PIHD may cause problems with placenta. The placenta may bleed or it may begin to 
separate from the wall of the uterus. Placenta insufficiency may also occur, a state in which the placenta fails to support appropriate fetal development because it cannot deliver the necessary amount of oxygen or nutrients to the fetus. If any of these complications occurs, fetal distress may develop ultimately leads to LAS.

Another finding of this study was the association of LAS with PSSL. This study revealed that neonates born to mothers with PSSL were nearly three times more likely to have LAS than their counterparts [AOR 2.63; 95\% Cl (1.399-4.944), $P=0.003$ ]. This is in line with studies done in Brazil, Sweden, and the USA [14, $18,32,33]$. This might be due to the fact that in the prolonged second stage of labor, there is a higher chance of cesarean delivery or manipulative vaginal deliveries and a chance of fetal distress, which could further affect the Apgar score.

This study also revealed that newborns born via cesarean delivery were about 2 times more probable to have a LAS than neonates born via spontaneous vaginal delivery. This finding is consistent with the studies done in Brazil, Sweden, and Australia [34-36]. This could be due to the lack of fetal chest compression during cesarean delivery which facilitates lung clearance from secretions and fluids. Similarly, drugs used for anesthesia during CS can also decrease uterine and placental circulation then it causes fetal hypoxemia which further leads to fetal morbidity including LAS [37].

Newborns of mothers with MSL during labor are almost seven times more likely to have LAS than newborns of the reference group [AOR 6.955; 95\% Cl (3.721-13.001), $P<0.001]$. This study is agreeable with studies done in Australia [AOR 3.1; 95\% Cl (2.0-4.61), $P<0.01]$, [36]. Notwithstanding this, a study from Brazil failed to support this result in which they reported there was no association of meconiumstained liquor with a LAS [14]. This could primarily be due to the quality of obstetrical care services being provided. Moreover, it could be also due to the fact that the Brazilian finding was reported from a relatively small sample size.

Moreover, this study also revealed newborns born with low birth weight were 4 times more likely to have LAS [AOR 4.38; $95 \% \mathrm{Cl}(2.216-8.657), P<0.001]$. This finding is similar to a study done in North West Ethiopia [20]. This could be explained by the fact that small babies might suffer from difficult birthing and might develop difficulty in cardiopulmonary transition and perinatal asphyxia which predisposes the newborns to various complications including LAS.

\section{Conclusion}

This study concluded that low Apgar score is significantly associated with obstetric factors like antepartum hemorrhage, pregnancy-induced hypertensive disorders and prolonged second stage of labor. Cesarean delivery also tremendously increased the odds of a low Apgar score. On top of this, meconium stained liquor and low birth weight were found to be a major determinant factors for a low Apgar score. Therefore, it is better for health care providers to keep their strength on early detection and management of newborns with LAS. 


\section{Abbreviations}

AOR: Adjusted Odds Ratio

APH: Antepartum Hemorrhage

LAS: low Apgar score

Cl: Confidence Interval

COR: Crude odds Ratio

CS: Cesarean Section

MRN: Medical Record Number

MSc: Master's Degree in Science

MSL: Meconium Stained Liquor

NICU: Neonatal Intensive Care Unit

PIHD: Pregnancy Induced Hypertensive Disorders

PROM: Premature Rupture of Membrane

PSSL: Prolonged Second Stage of labor

SPSS: Statistical Package for Social Sciences

\section{Declarations}

\section{Acknowledgments}

Praise to the Lord!! First and foremost, I just want to thank God for his endowments. Secondly, my heartfelt gratitude goes to my advisors Dr. MengistuWelday (Ph.D.) and Mr. Brhane Gebreegizabiher (MSC in Clinical Midwifery) for their tenacious guidance and precious comments throughout the work. My deepest gratitude also goes to my friends, Lemelem Karl HMIS office, Lemelem Karl hospital obstetric ward staff and data collectors for their unrelenting supports and suggestions. I owe them big! Last but not least I am also indebted to thank Mekelle University for offering me this opportunity.

\section{Ethics approval and consent}

Ethical clearance for the study was obtained from the Institutional Review Board (IRB) of Mekelle University with a designated IRB number of ERC 1156/2017 and a letter of permission was written from the chief executive director of Lemlem Karl General Hospital to Gyn- Obs ward head and HMIS office. 
Furthermore, confidentiality was not breached as the checklist developed is anonymous and does not identify mothers' personal information.

\section{Author's contributions}

MMG: Developed the proposal, analyzed data, and wrote the report and the manuscript. MWG and BGG: Organized overall process. TAH, GAG, M-AMR, KGT, NBY and HKM: Contributed in proposal writing, data collection and analysis. All authors have read and approved the final manuscript.

\section{Funding}

Mekelle University College of Health Sciences funded us for data collection and stationary materials.

\section{Availability of data and materials}

The datasets generated and/or analyzed during the current study are available from the corresponding author upon reasonable request.

\section{Consent for publication}

Not applicable.

\section{Competing interests}

The authors declare that they have no competing interests.

\section{Authors' information}

MMG: MSc in Clinical Midwifery, Department of Midwifery, College of Health Sciences, Aksum University, Aksum, Ethiopia. Email: mussiemulugeta@gmail.com

MWG:Phd in public health, Department of Midwifery, College of Health Sciences, Mekelle University, Mekelle, Ethiopia. Email: mengsteabw@gmail.com

BGG: MSc in Clinical Midwifery, Department of Midwifery, College of Health Sciences, Mekelle University, Mekelle, Ethiopia. Email: naodmgb@gmail.com

M-AMR: MSc in Clinical Midwifery, Department of Midwifery, College of Health Sciences, Mekelle University, Mekelle, Ethiopia. Email: meharimerry24@gmail.com

TAH: MSc in Clinical Midwifery, Department of Midwifery, College of Health Sciences, Aksum University, Aksum, Ethiopia. Email: tessotesa@gmail.com

GAG: MSc in Maternity and Neonatal Nursing, Department of Midwifery, College of Health Sciences, Aksum University, Aksum, Ethiopia. Email: gkaregawi@gmail.com 
KGT: MSc in Maternity Nursing, Department of Nursing, Faculty of Health Sciences, Woldia University, Woldia, Ethiopia. Email: keneanget@gmail.com

HKM: MSc in Clinical Midwifery, Department of Midwifery, Faculty of Health Sciences, Woldia University, Woldia, Ethiopia.Email: henokkumsa@gmail.com

NBY: MSc in Clinical Midwifery, Department of Midwifery, Faculty of Health Sciences, Woldia University, Woldia, Ethiopia. Email: bililignnigus@gmail.com

\section{References}

1. Apgar V. A proposal for a new method of evaluation of the newborn infant. CurrResAnesthAnalg. 1953;32(4):260-7.

2. ELK Grove Village II. Textbook of Neonatal Resuscitation. 6th ed. American Academy of Pediatrics and American Heart Association; 2011.

3. American College of obstetrics and Gynecology, Task Force on Neonatal Encephalopathy, American Academy of Pediatrics. Neonatal Encephalopathy and Neurologic Outcome. 2nd ed. Washington DC: American College of obstetricians and Gynecologists; 2014.

4. Oliveira TG de, Freire PV, Moreira FT, Moraes J da SB de, Arrelaro RC, Rossi S, et al. Apgar score and neonatal mortality in a hospital located in the southern area of São Paulo city, Brazil. Einstein (São Paulo). 2012;10(1):22-8.

5. Ehrenstein V. Association of Apgar scores with death and neurologic disability. Clin Epidemiol. 2009;1:45-53.

6. Fernández-carrocera LA, Guevara-fuentes CA, Salinas-ramírez V. Risk factors associated with mortality in infants weighing less than $1500 \mathrm{~g}$ using the CRIB II scale. Bol Med Hosp Infant Mex. 2011;68(5):330-6.

7. Abdullah A, Hort K, Butu Y, Simpson L. Risk factors associated with neonatal deaths: a matched case control study in Indonesia. Glob Heal Action. 2016;1(3):1-12.

8. Maria P, Soares S, Maestá I, Maria L, Suppo S, Felipe L, et al. Risk factors for perinatal death in two different levels of care: a case-control study. Reprod Health. 2014;11(11):1-7.

9. Suokas FE. The effects of Apgar score defined asphyxia on adulthood cognition: A longitudinal study. E-thesis (opinnäytteet), ethesis.helsinki.fi. 2017;1:23-26.

10. Cunha AA, Fernandes DS, Melo PF GM. Fatores associados à asfixia perinatal. Rev Bras Ginecol Obs. 2004;26(10):799-805.

11. Estimates developed by the UN Inter-agency group for child mortality estimation. Levels and trends in child mortality. New York City; 2015.

12. Central Statistical Agency, The DHS Program ICF. Ethiopian Demographic and Health Survey 2016. Addis Ababa, Ethiopia; 2017. 
13. Costa TL, Mota A, Duarte S, Araujo M, Ramos P, Machado HS, et al. Predictive factors of Apgar scores below 7 in newborns: Can we change the route of current eents? J Anesth Clin Res. 2016;7(10).

14. Salustiano Ema, Campos Jadb, Silvia Maria Ibidi Rr, Zugaib M. Low Apgar scores at 5 minutes in a low risk population: maternal and. Rev Assoc Med Bras. 2012;58(5):587-93.

15. Ehrenstein V, Pedersen L, Grijota M, Nielsen GL, Rothman KJ, Sørensen HT. Association of Apgar score at five minutes with long-term neurologic disability and cognitive function in a prevalence study of Danish conscripts. BMC Pregnancy Childbirth. 2009;9(14):1-7.

16. Bakhsha F, Yousefi Z, Aryaie M, Jafari SY. Comparison of Apgar score in new born by vaginal delivery and spinal anesthesia and its relationship with contributing factors. J Bas Res Med Sci. 2016;3(1):10-5.

17. Susilo SA, Pratiwi KN, Fattah ANA, Irwinda R, Wibowo N. Determinants of low Apgar score among preeclamptic deliveries in Cipto Mangunkusumo Hospital: a retrospective cohort study in 2014. Med J Indones. 2015;24(3):183-9.

18. Altman M. Prolonged second stage of labor is associated with low Apgar score corresponding author. Eur J Epidemiol. 2015;1-19.

19. Dassah ET, Odoi AT, Opoku BK. Stillbirths and very low Apgar scores among vaginal births in a tertiary hospital in Ghana: a retrospective cross-sectional analysis. BMC Pregnancy Childbirth. 2014;14(289):1-7.

20. Gudayu TW. Proportion and factors associated with low fifth minute Apgar score among singleton newborn babies in Gondar University referral hospital; North West Ethiopia . Afr Health Sci. 2017;17(1):6-11.

21. Kotlicka-antczak M, Smigielski J. Obstetrical complications and Apgar score in subjects at risk of psychosis. J Psychiatr Res. 2014;48:79-85.

22. Li J, Cnattingus S, Gissler M, Vestergaard M, Obel C, Ahrensberg J, et al. The 5-minute Apgar score as a predictor of childhood cancer: a population-based cohort study in five million children. BMJ Open. 2012;0:1-8.

23. Eun S, Lee JM, Yi DY, Lee NM, Kim H, Yun SW, et al. Assessment of the association between Apgar scores and seizures in infants less than 1 year old. Seizure Eur J Epilepsy. BEA Trading Ltd; 2016;37:48-54.

24. Zarkesh M, Momtazbakhsh M, Mojtabai H. Incidence and risk factors of pneumothorax in premature low birth weight infants under mechanical ventilation. Iran J Neonatol. 2013;4(3):1-6.

25. Pan C, Qian D, Zhu H, Yu J, Liu H. Apgar score and reduced vision in children aged 3 to 6 years. Graefes Arch Clin Exp Ophthalmol. Graefe's Archive for Clinical and Experimental Ophthalmology; 2017;255(2):401-5.

26. Siakwa M, Kpikpitse, D. Neonatal sepsis in rural Ghana: a case control study of risk factors in a birth cohort. Int J Res Med Heal Sci. 2014;4(5):77-88. 
27. Mgaya AH, Massawe SN, Kidanto HL, Mgaya HN. Grand multiparity: Is it still a risk in pregnancy? BMC Pregnancy Childbirth. 2013;13(241):1-8.

28. Adekanle DA, Adeyemi AS, Fadero FF. Ante-partum haemorrhage and pregnancy outcome in Lautech teaching hospital, southwestern Nigeria. J Med Med Sci. 2011;2:1243-7.

29. Maiti S, Kanrar P, Karmakar C, Bagdi S. Maternal and perinatal outcome in rural Indian women with placentaprevia. Br Biomed Bull. 2014;2(4):714-8.

30. Svenvik M, Brudin L, Blomberg M. Preterm Birth: A prominent risk factor for low Apgar scores. Biomed Res Int. 2015;2015:8.

31. Vats K, Paul M. Study of fetal outcome in hypertensive disorders of pregnancy in a tertiary care maternity hospital of Delhi. Int J Reprod Contraception, Obstet Gynecol. 2016;5(11):3773-7.

32. Cheng YW, Hopkins LM, Jr RKL, Caughey AB. Duration of the second stage of labor in multiparous women: maternal and neonatal outcomes. Am J Obstet Gynecol ogy. 2014;196:1-6.

33. Frisell T, Cnattingius S, Stephansson O. Prolonged second stage of labor is associated with low Apgar score. Eur J Epidemiol. 2015;1209-15.

34. Zorz Pdm De, Mad Jm, Rombaldi RI. Perinatal factors associated with $\mathrm{pH}<7.1$ in umbilical artery and Apgar 5 min $<7.0$ in term newborn Artigo. Rev Bras Ginecol Obs. 2012;34(8):381-5.

35. Berglund S, Pettersson H, Cnattingius S, Grunewald C. How often is a low Apgar score the result of substandard care during labour? BJOG. 2010;117:968-78.

36. Lai S, Flatley C, Kumar S. Perinatal risk factors for low and moderate five minute Apgar scores at term. J.ejogrb. 2017;1(8).

37. G Cassady. "Effect of cesarean section on neonatal body water spaces". New England Journal of Medicine. 1971.

\section{Supplementary Files}

This is a list of supplementary files associated with this preprint. Click to download.

- Mypointbypoint.docx 